\section{Screening USDA Lettuce (Lactuca sativa L.) Germplasm for Ability to Germinate under Cold Conditions}

\author{
Charlene M. Grahn \\ Department of Horticulture, Northwestern Washington Research and \\ Extension Center, Washington State University, Mount Vernon, WA 98273 \\ Barbara Hellier \\ Plant Germplasm Introduction and Testing Research Unit, USDA-ARS, \\ 59 Johnson Hall, Washington State University, Pullman, WA 99164-6402
}

Chris Benedict

Whatcom County Extension, Washington State University, 1000 N Forest Street, Suite 201, Bellingham, WA 98225

Carol Miles ${ }^{1}$

Department of Horticulture, Washington State University, Northwestern Washington Research and Extension Center, 16650 State Route 536, Mount Vernon, WA 98273

Additional index words. seed vigor, emergence, stand establishment, season extension, direct seeding, leafy vegetables

Abstract. Low temperatures can slow down emergence, decrease weed competitiveness, and lead to uneven crop maturity in direct-seeded crops such as baby leaf lettuce (Lactuca sativa L.). In this study, seeds of 103 single-parent lineage, homozygous lettuce accessions (53 cos and 50 leaf type) from the USDA National Plant Germplasm System (NPGS) and six commercial standard lettuce cultivars (three cos and three leaf type) were evaluated in replications for percent germination after 7 and 10 days at $5{ }^{\circ} \mathrm{C}$ in a germination chamber. Cos and leaf types were selected for this study as they are most commonly used for baby leaf lettuce production. Differences were observed among entries in percent seeds germinated after both 7 and 10 days. Overall, an average of $68 \%$ of seeds germinated after 7 days and $94 \%$ germinated after 10 days. Although several NPGS accessions had higher percent germination than the commercial cultivars, the average percent germination was not statistically different between the two seed sources at 7 or 10 days. Percent germination also did not differ between entries of cos and leaf type after 7 or 10 days. Similarly, no difference in percent germination between entries of dark and white seed color was observed after 7 or 10 days. No relationship between 100 seed weight and percent germination was observed after 7 days $\left(r^{2}=0.07\right)$ or 10 days $\left(r^{2}=\right.$ 0.13). Thus, lettuce seed type, color, and 100 seed weight do not appear to be good predictors of germination under cold conditions in lettuce. The accessions with the highest percent germination after 7 days at $5{ }^{\circ} \mathrm{C}$ have the potential to be used for the development of new lettuce cultivars suitable for an extended, early season production in temperate climates when soil temperature is lower than optimal for lettuce germination. Further studies are needed to assess the ability of these accessions to germinate rapidly under cold field soil conditions.

Lettuce is a cool-season crop that germinates optimally at an average temperature of $18{ }^{\circ} \mathrm{C}$ (Lafta and Mou, 2013). Established

Received for publication 15 May 2014. Accepted for publication 19 June 2015 .

We thank Dr. Jinguo Hu, USDA-ARS Supervisory Research Geneticist, for providing the seed for this study; Dr. Lindsey Du Toit, Mike Derie, and Barbara Holmes for procedural advice; and Dr. Tim Miller and Carl Libbey for providing germinator space. Funding support for this project from Washington State University Agricultural Research Center Emerging Research Issues is gratefully acknowledged.

${ }^{1}$ Corresponding author. E-mail: milesc@wsu.edu. after planting at $1 \mathrm{~cm}$ depth, whereas at $5{ }^{\circ} \mathrm{C}$ emergence occurs an average of $15 \mathrm{~d}$ after planting, and at $3{ }^{\circ} \mathrm{C}$ or lower, lettuce seed fails to germinate (Wagenvoort and Bierhuizen, 1977). Similarly, lettuce seed germination and emergence is suppressed at temperatures over $30{ }^{\circ} \mathrm{C}$ for most cultivars (Mayberry, 2003), though genotypes, specifically $L$. serriola, have been identified, which can germinate at $35{ }^{\circ} \mathrm{C}$ (Argyris et al., 2008).

Quick emergence of seedlings has long been the goal of horticulturists as a means of optimizing stand uniformity and maturity in direct-seeded crops (Fromme et al., 2014; Seale and Cantliffe, 1987). Low soil temperatures can increase the time to emergence, which leads to uneven crop maturity (Herner, 1986). This is problematic in a production system that uses once-over harvesting, as with mechanically harvested baby leaf lettuce. Slow stand establishment also results in a lengthened amount of time to complete canopy formation, which leads to increased weed emergence and growth (Légère and Schreiber, 1989).

Slow and inconsistent germination under cold soil temperature conditions is a primary barrier to extending the production season for lettuce in temperate regions. California and Arizona are the main production areas of leafy green salad crops, producing $96 \%$ of all lettuce grown in the United States, with 70\% of baby leaf salad crops produced in the Salinas Valley (City of Salinas EDO, 2013; USDA, 2014). The mild winter climate in these regions makes it possible to produce quality lettuce year-round (Smith et al., 2009). In contrast, lettuce production in temperate regions such as northwest Washington is limited to May through September, when soil temperature and moisture conditions are most favorable for crop emergence and growth. Spring soil temperature in northwest Washington averages $10^{\circ} \mathrm{C}$ (AgWeatherNet, 2014), and lettuce seeds emerge slowly and unevenly in these conditions.

Seed vigor comprises those properties that determine the potential for rapid, uniform emergence and development of normal seedlings under a wide range of field conditions (McDonald, 1993). Seed vigor is based on seed quality, environmental and maternal effects during seed crop production, as well as the genetic constitution of seeds which establishes their maximum physiological potential (Sun et al., 2007). Seed vigor encompasses several interrelated characteristics including rate and uniformity of germination and seedling growth, ability of seeds to germinate and emerge under unfavorable environmental conditions, and retention of the ability to germinate after storage. Seed vigor has already been shown to have a genetic component in other direct-seeded crops such as wheat (Triticum aestivum L.) (Rebetzke et al., 2004), cole crops including a Chinese kale (Brassica oleracea L.) $\times$ calabrese broccoli (B. oleracea L.) cross, a Brussels sprout $($ B. oleracea $\mathrm{L}$. $) \times$ cauliflower cross (B. oleracea L.) (Finch-Savage et al., 2010), rice (Oryza sativa L.) (Redona and 
Mackill, 1996), and sugar beet (Beta vulgaris L.) (De Los Reyes et al., 2003).

Seed morphological traits such as size and seedcoat color have been linked to seed vigor and emergence in many crop species, including lettuce. For example, watermelon (Citrullus lanatus var. lanatus L.) seed vigor, time to emergence, and viability can be determined according to seedcoat color, with dark seeds having better performance than light seeds (Mavi, 2010). In dry pea (Pisum sativum L.), single genotypes produce light, medium, and dark seed, and the color of the seed is linked to characteristics such as germination behavior, seedling salinity tolerance, and resistance to soilborne fungi, with dark seeds having the highest vigor under high salinity conditions and in the presence of soilborne pathogens (Atak et al., 2008). Lettuce seedcoat color heredity is such that varieties and genotypes can be classified as either dark or white seeded, with little to no variation in seed color observable within a genotype (Penaloza et al., 2005). Dark-seeded lettuce has been observed to possess higher percent germination and seed vigor as well as a lower pathogen susceptibility than white-seeded lettuce under $20^{\circ} \mathrm{C}$ conditions (Penaloza et al., 2005). Seed size and weight are associated with seed germination for maize (Zea mays L.), where, within a genotype, larger, heavier seeds generally have higher germination percentage and vigor than small seeds (Batistella et al., 2002). The relationship between seed weight and percent germination in lettuce has not been confirmed.

This experiment compared final germination at $5{ }^{\circ} \mathrm{C}$ for lettuce germplasm from the NPGS with standard cultivars used for baby leaf lettuce production by individual genotype, lettuce type (cos and leaf), seedcoat color, and seed weight. Identifying lettuce accessions from the NPGS collection that germinate rapidly under cold temperature conditions could lead to development of new cultivars with improved seedling vigor, which in turn could improve extended season production of direct-seeded lettuce in temperate regions.

\section{Materials and Methods}

Seed. Single-parent lineage, homozygous lettuce accessions were obtained from the USDA NPGS Western Region Plant Introduction Station (WRPIS), Pullman, WA. From the pure-line lettuce special collection of 298 lines, each of which is homozygous for all 322 single-nucleotide polymorphism markers genotyped by a high-throughput assay (Kwon et al., 2013), a total of 103 $\cos$ and leaf lettuce types were chosen for evaluation in this study as these are the lettuce types most commonly grown for baby leaf lettuce production. All seed obtained from the USDA NPGS was grown from a planting in 2011 (71 accessions) or 2012 (32 accessions) at the USDA Agricultural Research Service Central Ferry Farm, Washington. Seed was harvested in September or October in both years and was stored under controlled temperature and relative humidity $(\mathrm{RH})$ conditions $\left(4{ }^{\circ} \mathrm{C}, 20 \% \mathrm{RH}\right)$ at the WRPIS seed storage facility in Pullman. The accessions included 53 cos accessions (14 dark and 39 white seeded) and 50 leaf type accessions (27 dark and 23 white seeded), for a total of 41 dark- and 62 white-seeded accessions. Most accessions had greater than $90 \%$ germination in a germination test performed at $20{ }^{\circ} \mathrm{C}$. The six commercial standard cultivars (packaged for 2014; Johnny's Select Seeds, Winslow, ME) included in this study were three cos cultivars Parris Island, Coastal Star, and Defender (all white) and threeleaf cultivars Black Seeded Simpson, Two Star, and Waldmann's Green (all dark). These cultivars were chosen as they are commonly grown for commercial baby leaf lettuce production. Commercial standard cultivars were tested for germination at $20{ }^{\circ} \mathrm{C}$ from Dec. 2013 through Apr. 2014 and all had a final germination exceeding $94 \%$.

Assay methodology. At Washington State University Northwestern Washington Research and Extension Center in Mount Vernon, WA, lettuce seed germination was evaluated in a germination chamber (Hoffman Model SG 30; Hoffman Manufacturing Inc., Jefferson, OR) with a $12 \mathrm{~h}$ light:12 h dark cycle under fluorescent light (180 $\mu \mathrm{mol} \cdot \mathrm{s}^{-1} \cdot \mathrm{m}^{-2}$ ). For this study, the temperature was $5 \pm 1{ }^{\circ} \mathrm{C}$, and was recorded every $15 \mathrm{~min}$ throughout the study (HOBO data logger; Onset Computer Corporation, Bourne, MA). This study included three replicates of 50 seeds because of limited quantity of available seed. For each replicate, 50 seeds of each accession were placed into an acrylic container $(5.25 \times 5$ inches; Hoffman Manufacturing, Jefferson, OR) lined with Steel Blue blotter paper (Anchor Paper, Saint Paul, MN) and saturated with deionized water. Germination boxes were covered and placed randomly in the germination chamber. Number of seeds with normal germination was recorded for each accession at 7 and $10 \mathrm{~d}$ after placement in the germination chamber. Normal germination was determined according to the Association of Official Seed Analysts (AOSA) definition, which includes a normally developed hypocotyl, root tip, and primary root; and two normally developed cotyledons free of necrosis, disease, or discoloration (AOSA, 2009).

This experiment was carried out in two stages with the same germination equipment and methods used for both. First, the complete set of 103 NPGS germplasm accessions were assayed from 21 to 30 Sep. 2013. Second, a subset of 18 lettuce accessions (nine cos and nine leaf) plus six commercial standards (three cos and three leaf) were assayed from 7 to 16 Feb. 2015. The accessions included in the second assay were selected based on their percent germination at $7 \mathrm{~d}$ in the first assay; three cos and three leaf accessions were selected from each of the germination groups: high $(80 \%$ to $100 \%)$, moderate $(45 \%$ to $65 \%)$, or low $(0 \%$ to $25 \%)$ ). For each accession, five sets of 100 seeds were weighed to obtain the average 100 seed weight. For commercial standards, 100 seed weight was calculated from the average number of seeds per pound (data obtained from Johnny's Selected Seeds) for the specific seed lot of each commercial standard cultivar evaluated in this study. The 100 seed weight was compared with germination percentage at 7 and $10 \mathrm{~d}$, and seed weight was also compared between lettuce types and seed colors.

Statistical analysis. To evaluate consistency between the first and second assays, the percent germination at 7 and $10 \mathrm{~d}$ of the 18 accessions included in both assays were subjected to a paired $t$ test using PROC TTEST in SAS (Statistical Analysis System Version 9.3 for Windows; SAS Institute, Cary, NC). When no differences were detected between the performance of these 18 accessions at 7 or $10 \mathrm{~d}(P=0.45$ and 0.13 , respectively), data from the two assays were combined and "assay" (first and second) was incorporated into the statistical model as separate blocks. Combined data were subjected to analysis of variance (ANOVA) using PROC MIXED in SAS (Version 9.3 for Windows). Data were analyzed by entry, lettuce type (cos or leaf), and seedcoat color (dark or white). Raw data did not meet analysis assumptions of normality or homogeneity of variance; therefore, an attempt was made to identify an appropriate transformation meeting these assumptions using the range method described by Kirk (1982). When no transformation satisfied these assumptions, a nonparametric ANOVA was performed as described above after converting data into ranks using PROC RANK in SAS (Version 9.3 for Windows). Fisher's least significant difference test was used to compare treatment means for significant differences. No interactions were detected between main effects. Correlation between 100 seed weight and final germination at 7 and $10 \mathrm{~d}$ was determined with a simple linear regression model using PROC REG in SAS (Version 9.3 for Windows).

\section{Results}

Percent germination differed among entries at both 7 and $10 \mathrm{~d}$ (both $P=0.0001$ ). Of the 63 entries with high final germination (entries with the highest means separation level) at $7 \mathrm{~d}, 60$ were accessions and 3 were commercial standards (Table 1). Of the accessions with the highest final germination, 13 (seven cos and six leaf) had 100\% germination, while commercial leaf-type cultivars Black Seeded Simpson (91.7\%) and Defender $(91.1 \%)$, and cos-type cultivar Two Star $(83.7 \%)$ were statistically equivalent. Of the 26 entries with medium germination (entries with neither the highest nor the lowest means separation level), 24 were accessions and 2 were commercial standards ('Waldmann's Green', 60.4\% and 'Parris Island', 48.4\%). Of the 20 entries with low germination (entries with the lowest means separation level), 19 were accessions and one 
Table 1. Germination (\%) of 109 lettuce germplasm entries after 7 and $10 \mathrm{~d}$ at $5{ }^{\circ} \mathrm{C} .{ }^{\mathrm{z}}$

\begin{tabular}{|c|c|c|c|c|c|c|}
\hline \multirow{3}{*}{$\frac{\text { Entry }^{\mathrm{y}}}{\text { PI 169494-0 }}$} & \multirow[b]{2}{*}{ Lettuce type } & \multirow[b]{2}{*}{ Seed coat color } & \multicolumn{4}{|c|}{ Mean germination $(\%)^{\mathrm{x}}$} \\
\hline & & & \multicolumn{2}{|c|}{$7 \mathrm{~d}$} & \multicolumn{2}{|c|}{$10 \mathrm{~d}$} \\
\hline & Leaf & Dark & 100 & $\mathrm{a}^{\mathrm{w}}$ & 100 & $\mathrm{ab}$ \\
\hline PI 175737-0 & Leaf & Dark & 100 & $\mathrm{a}$ & 100 & $a b$ \\
\hline PI 566589-0 & Leaf & Dark & 100 & $\mathrm{ab}$ & 100 & $a b$ \\
\hline PI 278108-1 & $\operatorname{Cos}$ & Dark & 100 & $\mathrm{ab}$ & 100 & $\mathrm{ab}$ \\
\hline PI 342552-1 & Cos & Dark & 100 & $\mathrm{ab}$ & 100 & $\mathrm{ab}$ \\
\hline PI 175736-0 & Leaf & White & 100 & $a-c$ & 100 & $a b$ \\
\hline PI 342474-1 & Leaf & White & 100 & $a-c$ & 100 & $a b$ \\
\hline PI 344366-1 & Leaf & White & 100 & $a-c$ & 100 & $\mathrm{ab}$ \\
\hline PI 491025-0 & $\operatorname{Cos}$ & White & 100 & $a-d$ & 100 & $a b$ \\
\hline PI 491056-0 & Cos & White & 100 & $a-d$ & 100 & $a b$ \\
\hline PI 181946-1 & Cos & White & 100 & $a-d$ & 100 & $\mathrm{ab}$ \\
\hline PI 278081-1 & Cos & White & 100 & $a-d$ & 100 & $\mathrm{a}$ \\
\hline PI 288244-3 & $\operatorname{Cos}$ & White & 100 & $a-d$ & 100 & $\mathrm{a}$ \\
\hline PI 182210-1 & Leaf & Dark & 98.9 & $a-d$ & 98.9 & $a-c$ \\
\hline PI 164937-0 & Leaf & White & 98.7 & $a-d$ & 100 & $\mathrm{ab}$ \\
\hline PI 536764-0 & Leaf & Dark & 98.3 & $a-d$ & 98.3 & a-e \\
\hline PI 342541-4 & $\operatorname{Cos}$ & Dark & 97.6 & $a-d$ & 97.9 & a-e \\
\hline PI 142871-0 & Cos & Dark & 97.5 & a-e & 100 & $\mathrm{a}^{\mathrm{w}}$ \\
\hline PI 220665-1 & Cos & Dark & 97.3 & $a-f$ & 99.3 & $a b$ \\
\hline PI 278099-1 & $\operatorname{Cos}$ & White & 96.7 & $a-f$ & 100 & $a b$ \\
\hline PI 491042-0 & Cos & White & 95.6 & $\mathrm{a}-\mathrm{g}$ & 95.6 & $a-f$ \\
\hline PI 491053-0 & Cos & White & 94.9 & $a-g$ & 95.9 & $a-f$ \\
\hline PI 178923-1 & Leaf & Dark & 94.3 & $a-g$ & 94.3 & $a-f$ \\
\hline PI 536821-0 & $\operatorname{Cos}$ & Dark & 93.6 & $a-h$ & 97.2 & a-e \\
\hline PI 169493-0 & Cos & White & 93.6 & $a-h$ & 97.9 & a-e \\
\hline PI 491040-0 & $\operatorname{Cos}$ & White & 92.3 & $a-h$ & 95.2 & $a-f$ \\
\hline PI 491212-0 & Cos & White & 92.3 & $a-h$ & 96.5 & $a-f$ \\
\hline Black Seeded Simpson & Leaf & Dark & 91.7 & $\mathbf{a - h}$ & 100 & $a b$ \\
\hline PI 491080-0 & Leaf & White & 91.6 & $a-h$ & 97.9 & a-e \\
\hline Defender & $\operatorname{Cos}$ & White & 91.1 & $\mathbf{a - i}$ & 100 & $a b$ \\
\hline PI 171666-0 & $\operatorname{Cos}$ & Dark & 90.9 & $a-i$ & 97.9 & a-e \\
\hline PI 491032-0 & $\operatorname{Cos}$ & White & 90.8 & $a-i$ & 97.7 & a-e \\
\hline PI 536700-0 & Leaf & Dark & 88.3 & $a-i$ & 96.5 & $a-f$ \\
\hline PI 617943-1 & Leaf & White & 88.3 & $a-i$ & 95.9 & $a-f$ \\
\hline PI 491031-0 & $\operatorname{Cos}$ & Dark & 87.8 & $a-i$ & 98.3 & a-e \\
\hline PI 278080-1 & Leaf & White & 87.6 & $a-i$ & 95.9 & $a-f$ \\
\hline PI 536794-0 & $\operatorname{Cos}$ & White & 86.9 & $a-i$ & 97.2 & a-e \\
\hline PI 381933-0 & $\operatorname{Cos}$ & Dark & 84.3 & $a-i$ & 97.2 & a-e \\
\hline PI 177419-0 & Leaf & White & 84.3 & $a-i$ & 95.9 & $a-f$ \\
\hline PI 271476-1 & Leaf & Dark & 84 & $a-k$ & 97.3 & a-e \\
\hline Two Star & Leaf & Dark & 83.7 & a-k & 100 & $a b$ \\
\hline PI 536699-0 & Leaf & Dark & 83.3 & $a-1$ & 99.3 & $a b$ \\
\hline PI 368630-1 & $\operatorname{Cos}$ & White & 82.9 & $a-m$ & 96.5 & $a-f$ \\
\hline PI 289016-2 & Leaf & White & 82.3 & $a-m$ & 97.9 & a-e \\
\hline PI 358033-1 & $\operatorname{Cos}$ & White & 82.3 & $a-m$ & 93.9 & $a-f$ \\
\hline PI 536792-0 & Leaf & Dark & 81.6 & $a-m$ & 97.9 & a-e \\
\hline PI 617944-0 & Leaf & White & 80.9 & $a-n$ & 93.9 & $a-f$ \\
\hline PI 176980-0 & $\operatorname{Cos}$ & White & 77.6 & $a-o$ & 92.5 & $a-g$ \\
\hline PI 172918-0 & $\operatorname{Cos}$ & White & 75.6 & $a-o$ & 97.9 & $a-e$ \\
\hline PI 491078-0 & Leaf & Dark & 74.9 & $a-o$ & 95.2 & $a-f$ \\
\hline PI 617958-1 & Leaf & White & 74.9 & $a-o$ & 91.9 & $a-g$ \\
\hline PI 176588-0 & $\operatorname{Cos}$ & Dark & 74.3 & $a-o$ & 89.2 & $\mathrm{c}-\mathrm{h}$ \\
\hline PI 578884-0 & Leaf & White & 73.6 & $a-o$ & 97.2 & a-e \\
\hline PI 176579-2 & $\operatorname{Cos}$ & White & 73.6 & $a-o$ & 97.9 & a-e \\
\hline PI 491039-0 & $\operatorname{Cos}$ & White & 71.6 & $a-o$ & 97.2 & a-e \\
\hline W6 298171 & Leaf & Dark & 70.9 & $a-o$ & 98 & a-e \\
\hline PI 491084-0 & $\operatorname{Cos}$ & White & 70.9 & $a-p$ & 96.5 & $a-f$ \\
\hline PI 358001-1 & Leaf & White & 70.3 & $a-p$ & 82.5 & $g-j$ \\
\hline PI 278087-0 & $\operatorname{Cos}$ & White & 70.3 & $a-p$ & 97.2 & a-e \\
\hline PI 491045-0 & Cos & White & 70.3 & $a-p$ & 89.2 & $c-h$ \\
\hline PI 491213-0 & $\operatorname{Cos}$ & White & 70.3 & $a-q$ & 97.2 & a-e \\
\hline PI 508477-1 & Leaf & Dark & 69.6 & $a-r$ & 97.9 & a-e \\
\hline PI 146078-7 & Leaf & White & 68.9 & a-r & 97.9 & a-e \\
\hline PI 617958-3 & Leaf & Dark & 67.6 & b-s & 91.9 & $a-g$ \\
\hline PI 491034-0 & $\operatorname{Cos}$ & White & 66.9 & b-s & 97.2 & a-e \\
\hline PI 229762-0 & Cos & Dark & 65.6 & $\mathrm{c}-\mathrm{s}$ & 79.2 & $h-j$ \\
\hline PI 491008-0 & $\operatorname{Cos}$ & White & 65.6 & $\mathrm{c}-\mathrm{s}$ & 74.5 & $\mathrm{jk}$ \\
\hline PI 169509-1 & $\operatorname{Cos}$ & White & 65.6 & $\mathrm{c}-\mathrm{s}$ & 92.5 & a-g \\
\hline W6 3687 & Leaf & Dark & 64.9 & d-s & 64.9 & $\mathrm{kl}$ \\
\hline PI 146078-1 & Leaf & White & 64.9 & d-s & 97.2 & a-e \\
\hline PI 491049-0 & $\mathrm{Cos}$ & White & 62.9 & d-s & 96.5 & $a-f$ \\
\hline PI 491215-0 & Cos & White & 62.3 & $e-t$ & 82.5 & $g-j$ \\
\hline PI 358021-0 & Leaf & Dark & 61.6 & $f-t$ & 91.9 & a-g \\
\hline
\end{tabular}

(Continued on next page) was a commercial standard ('Coastal Star', $31.1 \%$ ). At $10 \mathrm{~d}, 20$ entries (16 accessions and four commercial standards) achieved $100 \%$ germination (Table 1). Of these entries, 11 were cos and nine were leaf type. Of the 21 entries with the lowest percent germination (all were accessions), 12 were cos and nine were leaf type.

Average percent germination for all accessions was $68 \%$ after $7 \mathrm{~d}$ and $94 \%$ after $10 \mathrm{~d}$. Average percent germination of accessions did not differ from the commercial standards after $7 \mathrm{~d}(68 \%$ both; $P=0.77)$ and $10 \mathrm{~d}$ (accessions $=94 \%$, commercial standards $=$ $99 \% ; P=0.29)$. No difference in percent germination was observed between cos and leaf lettuce types at $7 \mathrm{~d}(\cos =70 \%$, leaf $=$ $65 \% ; P=0.38)$ or $10 \mathrm{~d}(\cos =95 \%$, leaf $=$ $94 \% ; P=0.66)$. In addition, no difference was observed between entries with dark and white seedcoats at $7 \mathrm{~d}$ (dark $=70 \%$, white $=$ $66 \% ; P=0.13)$ or $10 \mathrm{~d}($ dark $=95 \%$, white $=$ $94 \% ; P=0.07$ ). No relationship was observed between 100 seed weight and lettuce type $(P=0.56), 100$ seed weight and seed color $(P=0.92)$, or 100 seed weight and seed source $(P=0.70)$ (Table 2$)$. Although statistically significant, there was no meaningful relationship observed between percent germination and 100 seed weight at either $7 \mathrm{~d}$ $\left(r^{2}=0.07, P=0.007\right)$ or $10 \mathrm{~d}\left(r^{2}=0.13, P=\right.$ $0.005)$.

\section{Discussion}

The seed assessed in this experiment was produced over two growing seasons, and commercial cultivar seed was produced at a different location than the NPGS accession seed. Therefore, the observed seed performance is potentially affected by genotype by environment interactions. After $7 \mathrm{~d}$ at $5{ }^{\circ} \mathrm{C}$, 13 NPGS accessions (seven cos and six leaf) had $100 \%$ germination, whereas the commercial cos and leaf cultivars with the highest final germination had $91.1 \%$ and $91.7 \%$ germination, respectively. Higher germination percentage at $7 \mathrm{~d}$ may result in faster stand establishment and canopy formation under field conditions (Orzolek, 1991). The 13 NPGS accessions with the highest percent germination at $7 \mathrm{~d}$ may be useful for developing new cultivars with high seed vigor in cold soil conditions for use in extended season production of direct-seeded lettuce.

In this study, lettuce type, seed weight, and seed color were not reliable predictors for final germination under cold temperature conditions. Large seed size and high seed weight have been linked to high seed vigor in crops such as wheat and corn (Hoy and Gamble, 1985; Lafond and Baker, 1986). This relationship has not been consistently observed in lettuce and no relationship was observed in this experiment.

Temperature conditions in this experiment did not favor the growth of any disease inoculum that may have been present on seeds, so no conclusions can be drawn from this study on the linkage between seedcoat color, size, or lettuce type on pathogen 
Table 1. (Continued) Germination (\%) of 109 lettuce germplasm entries after 7 and $10 \mathrm{~d}$ at $5{ }^{\circ} \mathrm{C}^{\mathrm{z}}$

\begin{tabular}{|c|c|c|c|c|c|c|}
\hline \multirow{3}{*}{$\begin{array}{l}\text { Entry }^{y} \\
\text { Waldmann's Green }\end{array}$} & \multirow{3}{*}{$\begin{array}{l}\text { Lettuce type } \\
\text { Leaf }\end{array}$} & \multirow{3}{*}{$\begin{array}{l}\text { Seed coat color } \\
\text { Dark }\end{array}$} & \multicolumn{4}{|c|}{ Mean germination $(\%)^{x}$} \\
\hline & & & \multicolumn{2}{|c|}{$7 \mathrm{~d}$} & \multicolumn{2}{|c|}{$10 \mathrm{~d}$} \\
\hline & & & 60.4 & f-t & 97.5 & $a-e$ \\
\hline PI 536826-0 & Leaf & Dark & 59.6 & g-t & 97.2 & a-e \\
\hline PI 358039-1 & $\operatorname{Cos}$ & White & 57.6 & $\mathrm{~h}-\mathrm{u}$ & 97.2 & a-e \\
\hline PI $615060-1$ & Leaf & Dark & 54.9 & $\mathrm{i}-\mathrm{u}$ & 95.2 & $a-f$ \\
\hline PI $278110-2$ & Leaf & White & 54.9 & $\mathrm{i}-\mathrm{u}$ & 97.9 & $a-e$ \\
\hline PI $176578-0$ & Leaf & Dark & 54.3 & $j-t$ & 99.7 & $a b$ \\
\hline PI 491062-0 & Leaf & White & 54.3 & $j-t$ & 87.7 & $f-i$ \\
\hline PI 278094-0 & Cos & Dark & 48.9 & $j-w$ & 95.2 & $a-f$ \\
\hline Parris Island & Cos & White & 48.4 & $\mathbf{j}-\mathbf{w}$ & 99.5 & $a b$ \\
\hline PI $601060-0$ & Leaf & Dark & 48.3 & $\mathrm{j}-\mathrm{w}$ & 96.5 & $a-f$ \\
\hline PI $583877-0$ & Leaf & White & 46.9 & $\mathrm{k}-\mathrm{x}$ & 97.9 & $a-e$ \\
\hline PI 172916-1 & Leaf & Dark & 46.3 & $1-\mathrm{x}$ & 95.9 & $a-f$ \\
\hline PI $536845-0$ & Leaf & White & 45.6 & $1-x$ & 63.9 & $\mathrm{kl}$ \\
\hline PI $285657-0$ & Cos & White & 45.3 & $\mathrm{~m}-\mathrm{x}$ & 95.3 & $a-f$ \\
\hline PI 491070-0 & Leaf & White & 43.6 & $n-v$ & 97.9 & $a-e$ \\
\hline PI $278109-1$ & Leaf & White & 43.3 & $n-y$ & 80 & $h-j$ \\
\hline PI 491079-0 & Leaf & Dark & 33.6 & o-w & 89.2 & $c-h$ \\
\hline PI 578883-0 & Leaf & White & 32.9 & $\mathrm{p}-\mathrm{y}$ & 96.5 & $a-f$ \\
\hline PI 278080-2 & Leaf & White & 31.6 & $q-y$ & 96.5 & $a-f$ \\
\hline Coastal Star & Cos & White & 31.1 & $\mathbf{r}-\mathbf{y}$ & 100 & $a b$ \\
\hline PI 491065-0 & Leaf & Dark & 30.9 & $s-y$ & 89.2 & $\mathrm{c}-\mathrm{h}$ \\
\hline PI 491022-0 & Cos & Dark & 30.9 & s-y & 97.9 & $a-e$ \\
\hline PI 342479-1 & Cos & White & 25.6 & $\mathrm{~s}-\mathrm{y}$ & 78.5 & $h-j$ \\
\hline W6 29841 & Cos & White & 21.8 & $t-y$ & 87.9 & $e-h$ \\
\hline PI 169509-4 & Cos & White & 20.9 & $u-y$ & 85.9 & $f-i$ \\
\hline PI 140394-0 & Cos & White & 20.7 & $v-y$ & 91.7 & c-g \\
\hline PI $175735-0$ & Leaf & White & 17.6 & $v-y$ & 96.5 & $a-f$ \\
\hline PI $171665-1$ & Cos & White & 17.3 & $v-y$ & 80 & $h-j$ \\
\hline PI $344367-1$ & Leaf & Dark & 16.3 & $v-y$ & 95.9 & $a-f$ \\
\hline PI 278100-0 & Cos & White & 16.3 & $v-y$ & 88.5 & d-h \\
\hline PI 274373-1 & Leaf & White & 15 & $w-y$ & 58.7 & $\operatorname{lm}$ \\
\hline PI 342524-1 & Leaf & Dark & 7.6 & xy & 95.9 & $a-f$ \\
\hline PI 491072-0 & Leaf & Dark & 6.9 & $\mathrm{y}$ & 63.9 & $\mathrm{k} 1$ \\
\hline PI 342523-1 & Leaf & Dark & 6.9 & $\mathrm{y}$ & 93.2 & $a-g$ \\
\hline PI 278072-0 & Cos & White & 6.9 & $\mathrm{y}$ & 85.9 & $f-i$ \\
\hline PI $577120-0$ & Cos & White & 6.9 & $\mathrm{y}$ & 93.9 & $a-f$ \\
\hline
\end{tabular}

${ }^{\mathrm{z}}$ Lettuce seed (three replicates, $\mathrm{n}=50$ per entry) screened at $5 \pm 1{ }^{\circ} \mathrm{C}$ temperature, $100 \%$ humidity, and $12 \mathrm{~h}$ light: $12 \mathrm{~h}$ dark in a Hoffman Model SG 30 germination chamber in acrylic containers $(5.25 \times 5$ inches; Hoffman Manufacturing, Jefferson, OR) on steel blue blotter paper (Anchor Paper, St. Paul, MN).

yPI and W6 lines obtained from the U.S. Department of Agriculture (USDA) National Plant Germplasm System (NPGS); commercial standard cultivars (bold) obtained from Johnny's Selected Seeds, Winslow, ME.

${ }^{\mathrm{x}}$ Mean percent germination as defined by Association of Official Seed Analysts (AOSA) definition of normal lettuce seed germination of three replicates of $n=50$ seeds per entry measured after 7 or $10 \mathrm{~d}$ in $5^{\circ} \mathrm{C}$ conditions.

${ }^{\text {w}}$ Mean separation of ranked mean percent germination $(P=0.0001)$ as determined by a Fisher's least significant difference test. Ranked means with at least one letter in common are not significantly different.

Table 2. Single-effect means for seed color and lettuce type, and interaction with 100 seed weight.

\begin{tabular}{lc}
\hline Effect & 100 seed wt $(\mathrm{g})^{\mathrm{z}}$ \\
\hline Seed color & \\
Dark & $0.1029^{\mathrm{y}}$ \\
White & 0.1025 \\
$P$ value & 0.92
\end{tabular}

Type

$\begin{array}{ll}\text { Cos } & 0.1034 \\ \text { Leaf } & 0.1020\end{array}$

$P$ value

0.56

Seed source

Accession $\quad 0.1026$

Standard 0.1028

$P$ value 0.70

${ }^{\mathrm{z}}$ No transformation satisfied the assumptions of normality for analysis of variance; therefore data were nonparametrically transformed using PROC RANK (SAS version 9.3 for Windows; SAS Institute, Cary, NC).

${ }^{\mathrm{y}}$ All means presented are nontransformed. under optimal field conditions for lettuce (Contreras and Barros, 2005; Smith et al., 1973). Field trials are needed to determine if accessions with the highest percent germination under cold germination chamber conditions $\left(5{ }^{\circ} \mathrm{C}\right)$ will also have higher percent germination under cold field soil conditions.

\section{Literature Cited}

AgWeatherNet. 2014. Washington State University Mount Vernon and 10 Mile Station Historic Data. Subset Used: July 1994 to July 2014. 15 Aug. 2014. <http://weather.wsu.edu/awn.php? page $=$ historicData $/>$.

Argyris, J., P. Dahal, E. Hayashi, D.W. Still, and K.J. Bradford. 2008. Genetic variation for lettuce seed thermoinhibition is associated with temperature-dependent expression of abscisic acid, gibberellin, and ethylene biosynthesis, metabolism, and response genes. Plant Physiol. 148(2):926-947.

Association of Official Seed Analysts (AOSA). 2009. Seed vigor testing handbook. Association of Official Seed Analysts, Ithaca, NY.

Atak, M., M.D. Kaya, G. Kaya, M. Kaya, and K.M. Kawar. 2008. Dark green colored seeds increase the seed vigor and germination ability in dry green pea (Pisum sativum L.). Pak. J. Bot. 40(6):2345-2354.

Batistella, F., F.V. Moro, and D.E. Carvalho. 2002. Relationships between physical, morphological, and physiological characteristics of seeds developed at different positions of the ear of two maize (Zea mays, L.) hybrids. Seed Sci. Tech. 30(1):97-106.

Cantliffe, D.J. 1989. Stand establishment. Acta Hort. 247:175-179.

City of Salinas Office of Economic Development. 2013. Agriculture and agribusiness. 19 July 2014. <http://www.businessinsalinas.com/ Key-Industries/Agriculture-Agribusiness.aspx/>.

Contreras, S. and M. Barros. 2005. Vigor tests on lettuce seed and correlation with emergence. Cien. Inv. Agr. 32(1):3-10.

De los Reyes, B.G., S.J. Myers, and J.M. McGrath 2003. Differential induction of glyoxylate cycle enzymes by stress as a marker for seedling vigor in sugar beet (Beta vulgaris L.). Mol. Gen. Genet. 269(5):692-698.

Finch-Savage, W.E., H.A. Clay, J.R. Lynn, and K. Morris. 2010. Towards a genetic understanding of seed vigour in small-seeded crops using natural variation in Brassica oleracea. Plant Sci. 176(6):582-589.

Fromme, D., B. Haggard, J. Lofton, and R. Mascagni. 2014. The importance of a rapid and uniform plant stand in corn. Louisiana St. Univ. Agric. Ctr. 11 Nov. 2013. <http://louisianacrops.com/ 2014/02/08/the-importance-of-a-rapid-and-uniform-plant-stand-in-corn/>.

Herner, R.C. 1986. Germination under cold soil conditions. HortScience 21:1118-1122.

Hoy, D.J. and E.E. Gamble. 1985. The effects of seed size and seed density on germination and vigor in soybean (Glycine max (L.) Merr.). Can. J. Plant Sci. 65(1):1-8

Kirk, R.E. 1982. Experimental design: Procedures for the behavioral sciences. 2nd ed. Brooks/ Cole Publishing Company, Belmont, CA.

Kuepper, G., J. Bachmann, and R. Thomas. 2002. Specialty lettuce \& greens: Organic production. Appropriate Tech. Transfer Rural Areas. Jan. 2002.

Kwon, S., I. Simko, B. Hellier., B. Mou, and J. Hu. 2013. Genome-wide association of 10 horticultural traits with expressed sequence tag-derived 
SNP markers in a collection of lettuce lines. Crop J. 1:25-33.

Lafond, G.P. and R.J. Baker. 1986. Effects of genotype and seed size on speed of emergence and seedling vigor in nine spring wheat cultivars. Crop Sci. 26(2):341-346.

Lafta, A. and B. Mou. 2013. Evaluation of lettuce genotypes for seed thermotolerance. HortScience 48:708-714.

Légère, A. and M.M. Schreiber. 1989. Competition and canopy architecture as affected by soybean (Glycine max) row width and density of redroot pigweed (Amaranthus retroflexus). Weed Sci. 37:84-92.

Mavi, K. 2010. The relationship between seed coat color and seed quality in watermelon Crimson sweet. Hort. Sci. (Prague) 37(2):62-69.

Mayberry, K. 2003. Temperature required for vegetable seedling emergence. Univ. Calif. Coop. Ext. Imperial Agric. Briefs. Feb. 2003.

McDonald, M.B. 1993. The history of seed vigor testing. J. Seed Technol. 17(2):93-100.

Orzolek, M.D. 1991. Stand establishment of vegetables in the field. HortTechnology 1:78-81.
Penaloza, P., G. Ramirez-Rosales, M.B. McDonald, and M.A. Bennett. 2005. Lettuce (Lactuca sativa, L.) seed quality evaluation using seed physical attributes, saturated salt accelerated aging, and the seed vigor imaging system. Electron. J. Biotechnol. 8(3):299-307.

Rebetzke, G.J., T.L. Botwright, C.S. Moore, R.A. Richards, and A.G. Condon. 2004. Genotypic variation in specific leaf area for genetic improvement of early vigour in wheat. Field Crops Res. 88(2):179-189.

Redona, E.D. and D.J. Mackill. 1996. Genetic variation for seedling vigor traits in rice. Crop Sci. 36(2):285-290.

Rubatzky, V. and M. Yamaguchi. 1997. World vegetables: Principles, production, and nutritive value. 2nd ed. Chapman \& Hall, New York, NY.

Seale, D. and D.J. Cantliffe. 1987. Improving stand establishment in lettuce (Lactuca sativa) through seed priming and soil amendments. Acta Hort. 198:37-42.

Shibutani, S. and K. Kinoshita. 1970. Studies on the ecological adaptation of lettuce. V. Winter frost injury. Okayama Univ. Sci. Rpt. Agr. 36:35-42.

Smith, O.E., N.C. Welch, and O.D. McCoy. 1973. Studies on lettuce seed quality: II. Relationship of seed vigor to emergence, seedling weight, and yield. J. Amer. Soc. Hort. Sci. 98:552-556.

Smith, R., S. Fennimore, and M. LeStrange. 2009. University of California IPM Pest Management Guidelines: Lettuce. Univ. Calif. Agr. Nat. Res. Publ. 3450.

Sun, Q., J. Wang, and B. Sunday. 2007. Advances on seed vigor physiological and genetic mechanisms. Agr. Sci. China 6(9):1060-1066.

United States Department of Agriculture. 2014. 2012 Census of agriculture state level data: Vegetables, potatoes, and melons harvested for sale in 2012 and 2007. U.S. Dept. Agr., Washington, D.C

Wagenvoort, W.A. and J.F. Bierhuizen. 1977. Some aspects of seed germination in vegetables. II. The effect of temperature fluctuation, depth of sowing, seed size and cultivar, on heat sum and minimum temperature for germination. Sci. Hort. 6:259-270. 